\title{
Selinexor, a selective inhibitor of nuclear export, enhances the anti-tumor activity of olaparib in triple negative breast cancer regardless of BRCA1 mutation status
}

\author{
Hélène Marijon ${ }^{1,2}$, Sigal Gery ${ }^{1}$, Hua Chang ${ }^{3}$, Yosef Landesman $^{3}$, Sharon Shacham ${ }^{3}$, \\ Dhong Hyun Lee ${ }^{1}$, Aimery de Gramont ${ }^{2,4}$ and Harold Phillip Koeffler ${ }^{1,5}$ \\ ${ }^{1}$ Cedars-Sinai Medical Center, Division of Hematology/Oncology, University of California, Los Angeles, CA 90048, USA \\ ${ }^{2}$ Department of Medical Oncology, Franco-British Hospital (Fondation Cognacq-Jay), Levallois-Perret, France \\ ${ }^{3}$ Karyopharm Therapeutics Inc., Newton, MA 02459, USA \\ ${ }^{4}$ Statistical Unit, Aide et Recherche en Cancérologie Digestive Foundation, Levallois-Perret, France \\ ${ }^{5}$ Cancer Science Institute of Singapore, National University of Singapore 117599, Singapore \\ Correspondence to: Hélène Marijon, email: helene.marijon@cognacq-jay.fr \\ Keywords: selinexor; XPO1; olaparib; triple negative breast cancer; BRCA1 \\ Received: May 07, $2021 \quad$ Accepted: July 28, $2021 \quad$ Published: August 31, 2021
}

Copyright: ( 2021 Marijon et al. This is an open access article distributed under the terms of the Creative Commons Attribution License (CC BY 3.0), which permits unrestricted use, distribution, and reproduction in any medium, provided the original author and source are credited.

\section{ABSTRACT}

Triple negative breast cancer (TNBC) is a deadly disease with limited treatment options. Selinexor is a selective inhibitor of nuclear export that binds covalently to exportin 1 thereby reactivating tumor suppressor proteins and downregulating expression of oncogenes and DNA damage repair (DDR) proteins. Olaparib is a poly (ADP-ribose) polymerase (PARP) inhibitor approved for the treatment of patients with breast cancer harboring BRCA mutations. We examined the effects of cotreatment with selinexor and olaparib in TNBC cell lines. BRCA1 wildtype (BRCA1-wt) and BRCA1 mutant (BRCA1-mut) TNBC cell lines were treated with selinexor and/ or olaparib and effects on cell viability and cell cycle were evaluated. The effects of treatment were also evaluated in mouse xenograft models generated with BRCA1-wt and BRCA1-mut TNBC cell lines. Treatment with selinexor inhibited cell proliferation and survival of all TNBC cell lines tested in vitro. This effect was enhanced following treatment of the cells with the combination of selinexor and olaparib, which showed synergistic effects on tumor growth inhibition in MDA-MB-468-derived (BRCA1-wt) and MDA-MB-436-derived (BRCA1-mut) xenografts. As co-treatment with selinexor and olaparib exhibits anti-tumor activity regardless of BRCA1 mutation status, the clinical implications of the combination warrant further investigation.

\section{INTRODUCTION}

Breast cancer is one of the three most common cancers (together with lung and colorectal cancers) in the United States, accounting for $30 \%$ of female cancers [1]. Approximately $15-20 \%$ of breast cancers are triple-negative breast cancer (TNBC), which usually corresponds to basal breast cancer and is characterized by the absence of HER2, estrogen, and progesterone receptors. Patients with TNBC have poor prognosis with the worst disease-free and overall survival rates of all breast cancer types.
$B R C A 1$ and BRCA2 are tumor suppressor genes responsible for the repair of double-strand DNA breaks (DSBs) via homologous recombination (HR) [2]. Germline BRCA1 and BRCA2 mutations have been identified in $10-20 \%$ of TNBC patients and $3-5 \%$ of TNBC patients harbor $B R C A$ somatic mutations $[3,4]$.

Poly (ADP-ribose) polymerases (PARPs) are a group of enzymes activated by DNA damage. PARP1 and PARP2 assist in the repair of single-strand breaks (SSBs) through base excision repair. PARP inhibition traps the PARP-DNA complex at replication forks, leading SSBs to become DSBs that accumulate and ultimately lead 
to cell apoptosis if not corrected by appropriate repair mechanisms. As cells deficient in BRCA1/2 cannot repair DSBs, they are particularly sensitive to the effects of PARP inhibition, resulting in synthetic lethality in tumor cells carrying the mutation while normal cells are spared [5]. Olaparib was the first PARP inhibitor (PARPi) approved by the United States Food and Drug Administration for the treatment of patients with deleterious germline $B R C A$-mutant, HER2-negative metastatic breast cancer who have been previously treated with chemotherapy [6]. Preclinical and clinical evidence have demonstrated that PARPi also affect cancer cells with other DNA repair mechanism defects (i.e., cells not harboring BRCA1/2 mutations) [7]. Although 35\% of all TNBC cases exhibit homologous recombination (HR) repair deficiency, in clinical practice, olaparib does not benefit TNBC patients without BRCA1/2 mutations [8]. One strategy to expand the TNBC patient population that could benefit from this treatment is to combine PARPi with agents that induce DNA damage. PARPi have been shown to act as chemosensitizers and radiosensitizers but combination treatment of olaparib with chemotherapy (cisplatin, gemcitabine or irinotecan) has shown high toxicity [9-11]. PARPi can also be combined with less toxic targeted therapies that have overlapping effects in DNA damage repair (DDR) pathways.

The nuclear export protein exportin 1 (XPO1/ CRM1) mediates the transport of over 200 proteins, including several key cell cycle regulators and tumor suppressors including APC, FOXO proteins, NPM1, p53, p21CIP, p27KIP1, BRCA1, and BCR-ABL. These proteins act as tumor suppressors when localized to the nucleus and enable cell proliferation and survival when exported to the cytoplasm [12-15]. XPO1 overexpression has been linked to poor prognosis and drug resistance in solid and hematological malignancies [16-18] including breast cancer [19].

Selinexor is an oral selective inhibitor of nuclear export (SINE) that binds covalently to cysteine 528 in the cargo binding pocket of XPO1 and inhibits its activity [20-22]. This inhibition causes accumulation of tumor suppressor proteins in the nucleus of malignant cells and blocks protein translation of oncogenes that drive cell proliferation, leading to cell cycle arrest and apoptosis of malignant cells [20-24].

Selinexor has demonstrated potent anti-cancer activities in multiple preclinical models of TNBC. The growth of 14 TNBC cell lines was inhibited by selinexor independently of PTEN, PIK3CA, TP53 or RAS mutation status. In vivo, selinexor reduced tumor growth by $42 \%$ (range 31 to $73 \%$ ) in four patient-derivedTNBC xenograft models [25]. Furthermore, in an animal model of basal breast cancer, selinexor significantly reduced tumor cell growth to approximately one-third the volume of tumors observed in 5-fluorouracil-treated animals [14].
In clinical practice, selinexor as monotherapy was well tolerated in patients who received several lines of chemotherapy for TNBC and showed a clinical benefit rate of $30 \%$, but no objective response [26]. As selinexor downregulates DDR proteins, it is mechanistically an ideal drug partner for PARPi, such as olaparib. The objective of the current study was to determine whether selinexor could increase the sensitivity of TNBC - with or without $B R C A 1 / 2$ mutations - to olaparib.

\section{RESULTS}

\section{Synergistic anti-proliferative effect of selinexor with olaparib in a panel of TNBC cell lines}

As different TNBC molecular subtypes often demonstrate different biological behavior, seven TNBC cell lines from representing subtypes were selected to evaluate the anticancer effects of selinexor and olaparib in vitro (Table 1). To examine the effects of selinexor and olaparib, various concentrations of olaparib - with or without selinexor - were applied to the cells for 72 hours and then cell viability was evaluated. Two BRCA1-mut cell lines, HCC-1937 and MDA-MB-436, showed very different sensitivity to olaparib, with MDA-MB-436 being the most sensitive cell line tested (IC50 $17.5 \mu \mathrm{M}$ ) and HCC-1937 being the most resistant cell line tested (IC50 $>300 \mu \mathrm{M}$ ).

A non-constant drug ratio analysis (Figure 1A) showed synergism between selinexor and olaparib for all concentrations in all TNBC cell lines regardless of their BRCA1 mutation status, except in MDA-MB-453 which showed additive effects. Interestingly, the ER-/ HER2+ BRCA1-mut cell line, BT474 (Figure 1B), showed similar effects. Synergism between both drugs was confirmed by using a constant drug ratio analysis. For that analysis, MDA-MB-468, MDA-MB-231 and HCC1937 were treated with 5 therapeutic combinations of olaparib - with or without selinexor-for 72 hours (Figure 1C). The combination index (CI) was lower than 1 in all 15 combinations. In the HCC-1937 and MDA-MB-468 cell lines, CI at ED50 was lower than 0.5 indicating high synergism.

\section{Selinexor enhances the effect of olaparib on apoptosis in $B R C A 1$-wt and $B R C A 1$-mut cell lines}

Cell cycle and apoptosis analysis were performed following exposure of TNBC cell lines with $B R C A 1$ wt (MDA-MB-231 and MDA-MB-468) and BRCA1mut (HCC-1937) to olaparib and selinexor (alone or in combination). G2-arrest was induced as early as 24 hours after olaparib treatment of MDA-MB-231 and MDAMB-468, and after 48 hours of HCC-1937 (Figure 2A). No significant effects on cell cycle were observed when the 
Table 1: Characteristics of studied cell lines

\begin{tabular}{lllll}
\hline Cell line & Subtype & BRCA1 status & TP53 status & Other mutations \\
\hline HCC1937 & TNBC BL1 & MUT & MUT & MAPK13, MDC1 \\
MDA-MB-231 & TNBC MSL & WT & MUT & BRAF, CDKN2A, KRAS, NF2, PDGFRA \\
MDA-MB-436 & TNBC MSL & MUT & MUT & \\
MDA-MB-468 & TNBC BL1 & WT & MUT & PTEN, RB1, SMAD4 \\
BT-549 & TNBC M & WT & MUT & PTEN, RB1 \\
Hs578T & TNBC MSL & WT & MUT & HRAS, CDKN2A \\
MDA-MB-453 & TNBC LAR & WT & WT & PTEN, CDH1 \\
BT474 & Luminal B (HER2+) & MUT & MUT & \\
\hline
\end{tabular}

Abbreviations: BL1: basal-like 1, LAR: luminal androgen receptor, M: mesenchymal, MSL: mesenchymal stem-like, MUT: mutated, TNBC: triple-negative breast cancer, WT: wildtype.

three TNBC cell lines were treated with selinexor alone. Interestingly, selinexor combined with olaparib increased the percentage of cells arrested at $\mathrm{G} 2 / \mathrm{M}$ in the $B R C A 1$-mut cell line HCC-1937 but not in BRCA1-wt cell lines MDAMB-231 and MDA-MB-468 (Figure 2A).

Apoptosis studies showed that $9 \%$ of the MDAMB-231 cells were apoptotic after exposure to olaparib for 72 hours, whereas $24 \%$ of the cells became apoptotic after exposure to selinexor. When the cells were exposed to both drugs, $36 \%$ of the cells became apoptotic after 72 hours. Similar results were seen for the other TNBC cell line expressing BRCA1-wt, MDA-MB-468, whereby $38 \%$ of cells underwent apoptosis after exposure to olaparib and selinexor for 72 hours, compared to $19 \%$ after treatment with olaparib and $25 \%$ following treatment with selinexor. Exposure of the BRCA1mut HCC-1937 cell line to olaparib and selinexor for 72 hours resulted in apoptosis of $49 \%$ of the cells as compared to apoptosis of $32 \%$ of the cells after exposure to olaparib and $28 \%$ after exposure to selinexor for 72 hours (Figure 2B). Thus, co-treatment with olaparib and selinexor had an enhanced effect on apoptosis in all three TNBC cell lines, regardless of their BRCA1 mutational status.

\section{Selinexor and olaparib synergistically inhibit the growth of BRCA1-mut MDA-MB-436 xenografts in vivo}

Following the observed synergy of selinexor + olaparib in vitro, the effect of the combination was examined on MDA-MB-436 (BRCA1-mut) xenografts in immunodeficient mice. MDA-MB-436 cells were chosen due to the very slow growth of HCC-1937 in vitro. When tumor volumes reached $100 \mathrm{~mm}^{3}$, mice were randomly assigned to one of 4 different treatment groups: placebo, olaparib, selinexor or olaparib + selinexor. During treatment, digestive toxicities (diarrhea and weight loss $>10 \%$ ) were observed in mice receiving selinexor and selinexor + olaparib as early as day 5. Consequently, selinexor was stopped on Day 5 in both groups and reintroduced on Day 10 at a lower dose $(5 \mathrm{mg} / \mathrm{kg})$. Two mice were sacrificed prior to the end of the experiment: one in the selinexor + olaparib group due to weight loss $>20 \%$, and one in the olaparib group due to excessive tumor growth. One mouse in the control group died (the reason for death is unknown).

Tumor growth decreased in both the selinexor and combination group as early as day 4 whereas olaparib alone did not elicit this effect. From Day 10 onwards, selinexor + olaparib had a greater inhibitory effect on tumor growth compared to selinexor or olaparib alone (Figure 3A). At the end of the study, mean tumor volume was $748.5 \pm 154.7 \mathrm{~mm}^{3}$ (8 tumors) with control, 821.0 $\pm 168.4 \mathrm{~mm}^{3}$ (8 tumors) with olaparib, $465.6 \pm 44.2$ $\mathrm{mm}^{3}$ (10 tumors) with selinexor, and $230.3 \pm 92.9 \mathrm{~mm}^{3}$ (8 tumors) with selinexor + olaparib $(p=0.006$ by ANOVA) (Figure 3B). Average tumor growth inhibition (TGI) compared to the control group was $42 \%$ with selinexor, and 79\% with selinexor + olaparib (Figure 3A). Although no significant tumor growth inhibition was observed for the olaparib single agent treatment group when compared with the control, tumor volumes were significantly lower in the combination group compared to each of the single agent groups demonstrating synergistic effect of the combination (groups were compared 2 by 2 using a non-paired $t$-test).

Similarly, mean tumor weight was significantly lower with selinexor + olaparib $(0.48 \pm 0.2 \mathrm{~g})$ compared to the other treatment groups $(1.56 \pm 0.41 \mathrm{~g}$ with control, $1.84 \pm 0.46 \mathrm{~g}$ with olaparib, $1.05 \pm 0.12 \mathrm{~g}$ with selinexor; $p=0.026$ by ANOVA, Figure 3C).

Macroscopic analysis revealed that tumors receiving selinexor + olaparib were less vascularized than those receiving other treatments. Interestingly, the largest tumor in the selinexor + olaparib group was mainly necrotic (Figure 3D). This was confirmed by Ki67 staining in the 2 largest tumors from this group, which showed a thin layer of tumoral cells surrounding large areas of necrosis (data not shown). 
Microscopic analysis using ApopTag $^{\circledR}$ staining confirmed an increase in apoptotic cells with selinexor compared to control, and with selinexor + olaparib compared to both monotherapies. Ki67 staining decreased with selinexor + olaparib compared to the 3 other treatments (Figure 3E).
Selinexor and olaparib have synergistic effects in vivo on the growth of xenografts derived from MDA-MB-468, a BRCA1-wt TNBC cell line

We repeated the same experiment with xenografts derived from MDA-MB-468 (BRCA1-wt) except for the
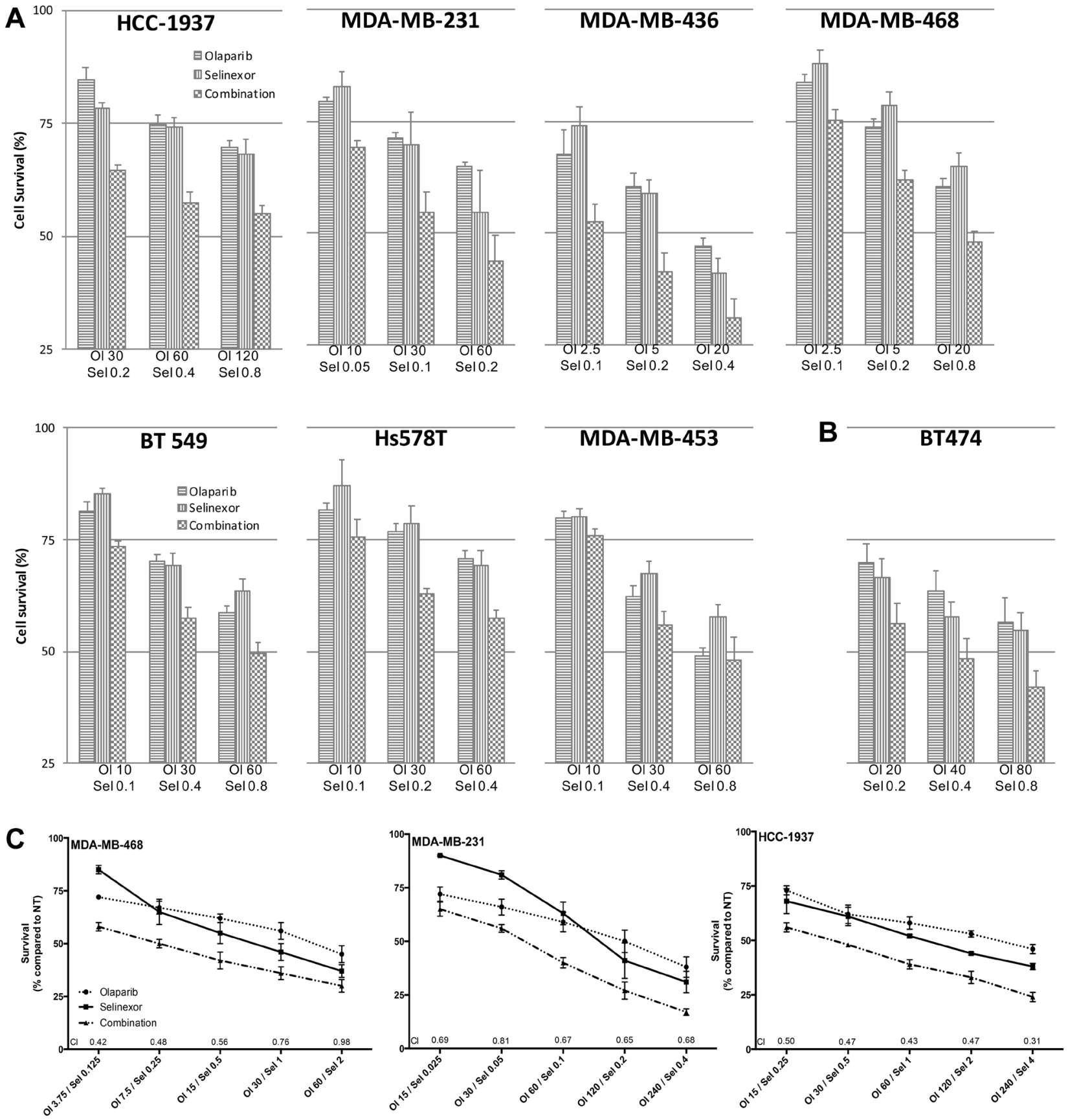

Figure 1: Synergistic anti-proliferation effects of selinexor and olaparib in a panel of TNBC cell lines. (A) Antiproliferation dose-response effect of olaparib and selinexor (alone and combined) in a panel of seven TNBC cell lines. Each bar reflects median \pm standard error of the mean (SEM) of 3 experiments. Combination Index (CI) was determined using the CompuSyn software. (B) Antiproliferation dose-response effect of olaparib and selinexor (alone and combined) in a HER2-amplified BRCA-mutated breast cancer cell line (BT474). Each bar depicts median \pm SEM of 3 experiments. (C) Cell survival after exposure to olaparib and selinexor (alone and combined) using a constant ratio between the drugs. Each data point indicates median \pm SEM of 3 experiments. Concentrations in $\mathrm{mM}$. Abbreviations: Ol: olaparib; Sel: selinexor; CI: combination index. 
dose of selinexor (decreased to $5 \mathrm{mg} / \mathrm{kg}$ ). As xenograft growth was slower, the experiment was stopped on Day 59. At the end of the experiment, mean tumor volume was $1346 \pm 111 \mathrm{~mm}^{3}$ (SEM, 8 tumors) with control, 338 $\pm 108 \mathrm{~mm}^{3}$ (8 tumors) with olaparib, $384 \pm 114 \mathrm{~mm}^{3}$ (8 tumors) with selinexor, and $136 \pm 111 \mathrm{~mm}^{3}$ (5 tumors due to 3 complete responses) with selinexor + olaparib. Average TGI compared to control was $81 \%$ with olaparib, $77 \%$ with selinexor and $98 \%$ with selinexor + olaparib, indicating a synergistic effect of the combination treatment (Figure 4A). Treatment with selinexor + olaparib showed a statistically significant reduction in tumor growth relative to olaparib or selinexor alone ( $p=0.0207$ for both).

Interestingly, the effects of the combined treatment were observed as early as Day 20. Moreover, three complete responses were observed with selinexor + olaparib (Figure 4B).

Although a microscopic analysis did not reveal major changes after ApopTag ${ }^{\circledR}$ staining, Ki67 staining was weaker with selinexor + olaparib compared to other treatments (Figure 4C).

\section{Effects of olaparib and selinexor on HR in $B R C A 1-w t$ TNBC cell line}

Additional experiments, focusing on the HR pathway in cells expressing wildtype BRCA1, were performed based on the mechanism of action of olaparib. RAD51, which plays a major role in HR of DNA during DSB repair and the $\mathrm{H} 2 \mathrm{~A}$ histone family member $\mathrm{X}$ that becomes phosphorylated on serine 139 in reaction to DNA DSB, P-H2AX, were analyzed by western blot and immunofluorescent staining. After treatment with selinexor, RAD51 expression decreased whereas no changes in $\mathrm{P}-\mathrm{H} 2 \mathrm{AX}$ expression were observed. After treatment with olaparib, P-H2AX expression increased. After exposure to both treatments, P-H2AX was further induced, suggesting lack of HR and DSB accumulation (Figure 5A). These observations were confirmed by immunofluorescent analysis of MDA-MB-468 cells (Figure 5B). A similar trend was observed following immunohistochemistry of MDA-MB-468-derived tumor xenografts: P-H2AX staining was significantly increased
A
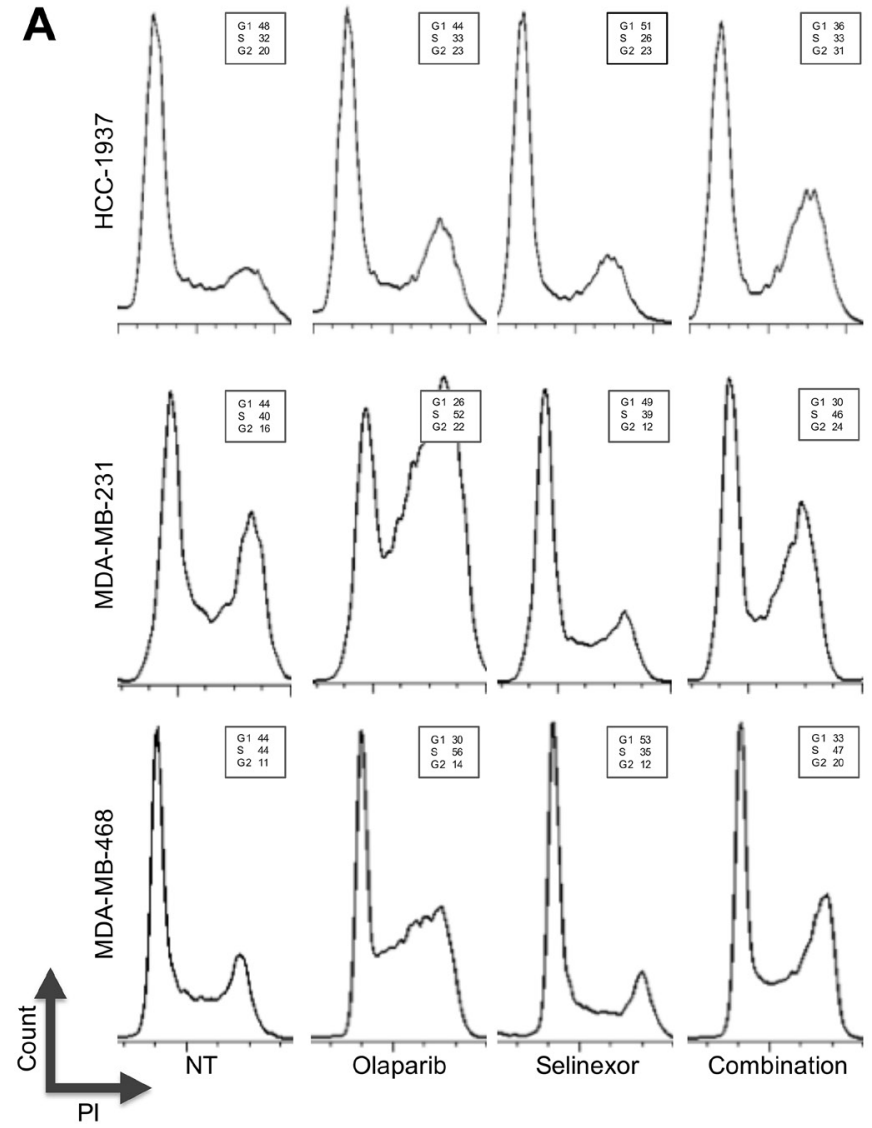

B
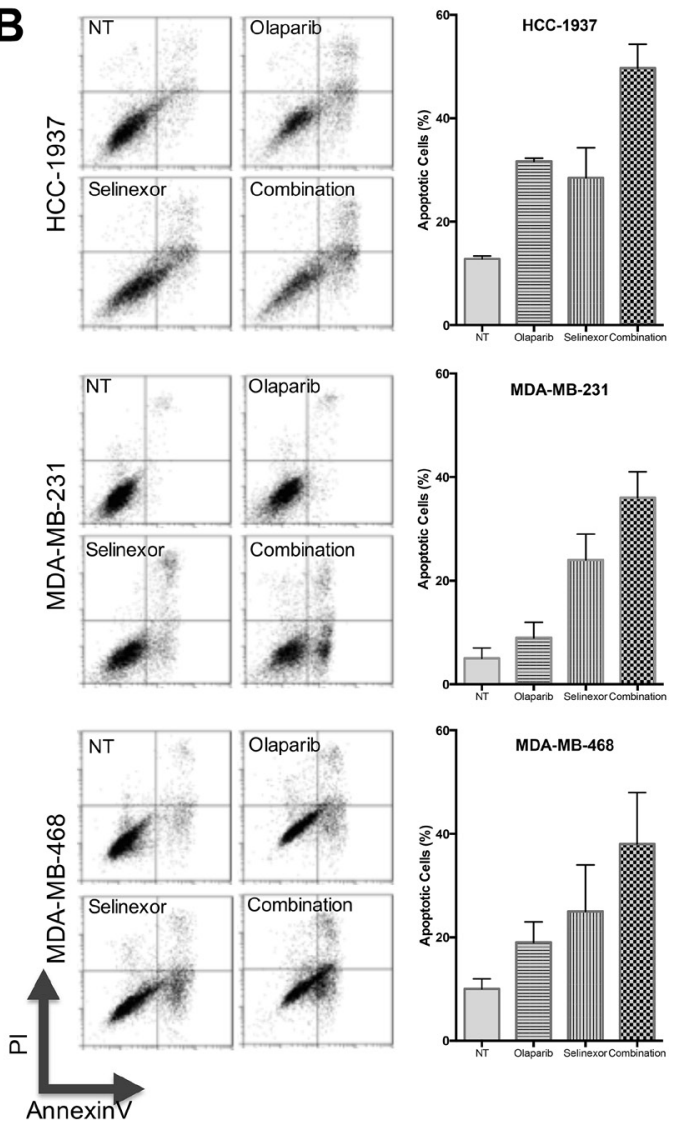

Figure 2: Effects of treatment with olaparib and selinexor (alone and in combination) on cell cycle and apoptosis of 2 BRCA1-wt TNBC cell lines (MDA-MB-231 and MDA-MB-468) and a BRCA1-mut cell line (HCC-1937). (A) Cell cycle analysis of HCC-1937, MDA-MB-231 and MDA-MB-468 cells. Cells were stained with PI and Annexin-V-FITC and analyzed by flow cytometry (representative results of 3 experiments). (B, left panel) Apoptosis of TNBC cells after exposure to olaparib and selinexor for 72 hours (alone and in combination). Cells were stained with PI and AnnexinV-FITC and analyzed by flow cytometry (representative results of 3 experiments). (B, right panel) For each cell line, the chart depicts the mean percentage of apoptotic cells \pm SEM of 3 experiments. 
in tumors treated with selinexor + olaparib compared to the other groups (Figure 5C). These results suggest that the combination induced DNA damage in MDA-MB-468, which could partly explain the synergy observed between olaparib and selinexor.

\section{DISCUSSION}

In search of effective treatment options for TNBC, we tested PARPi olaparib and SINE drug selinexor as single agents and in combination in seven TNBC cell
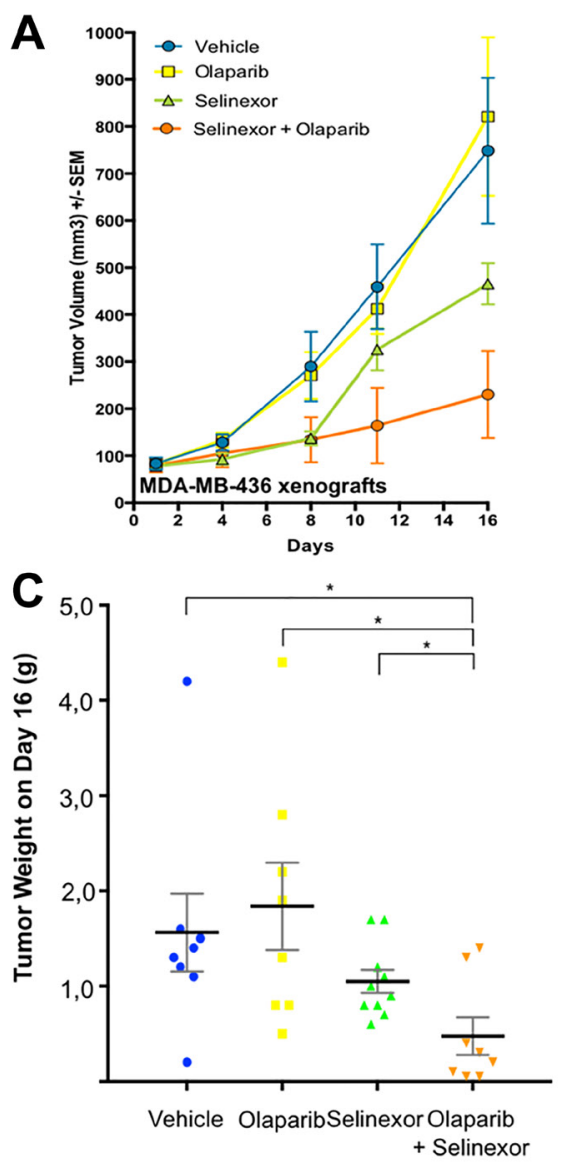

D
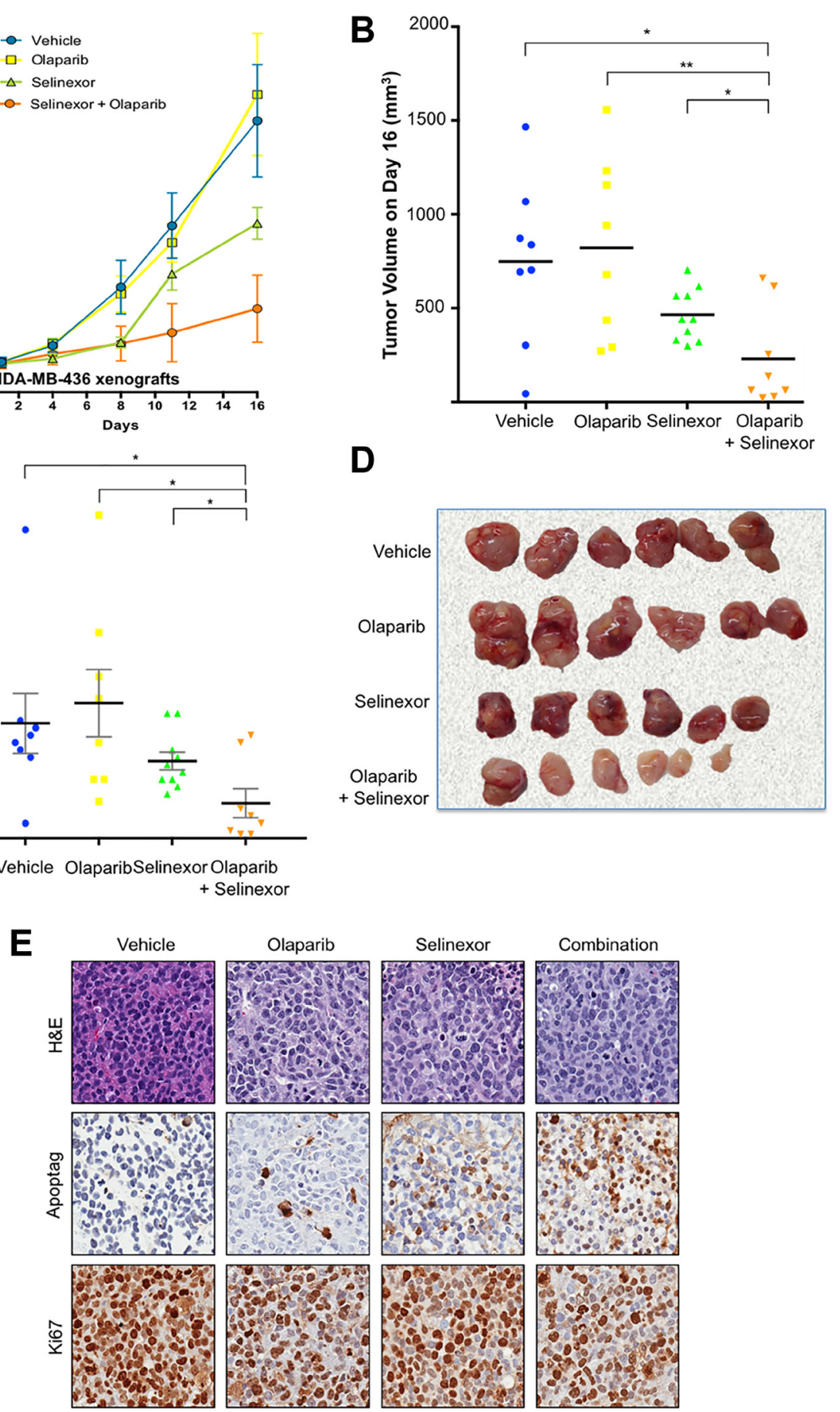

Figure 3: Synergistic effect of olaparib and selinexor on the growth of BRCA1-mut MDA-MB-436 xenografts in immunodeficient mice. (A) Volumetric growth of the tumor xenografts. Each data point represents mean tumor volume \pm SEM. Drug doses and mode of administration: olaparib $50 \mathrm{mg} / \mathrm{kg}$, intraperitoneal, 5 days/week; selinexor $7.5 \mathrm{mg} / \mathrm{kg}$, oral, 3 days $/$ week. (B) Tumor volume at the end of the experiment (Day 16). (C) Tumor weight at the end of the experiment (Day 16). (D) Representative tumors from each treatment group at the end of the experiment. (E) Representative images showing staining with H\&E, ApopTag ${ }^{\circledR}$ and Ki67 of tumors from each treatment group. 
lines comprising four different subtypes with or without BRCA1 mutations. Synergistic effects of olaparib and selinexor on cell viability and proliferation were observed in all TNBC cell lines tested, regardless of their BRCAI

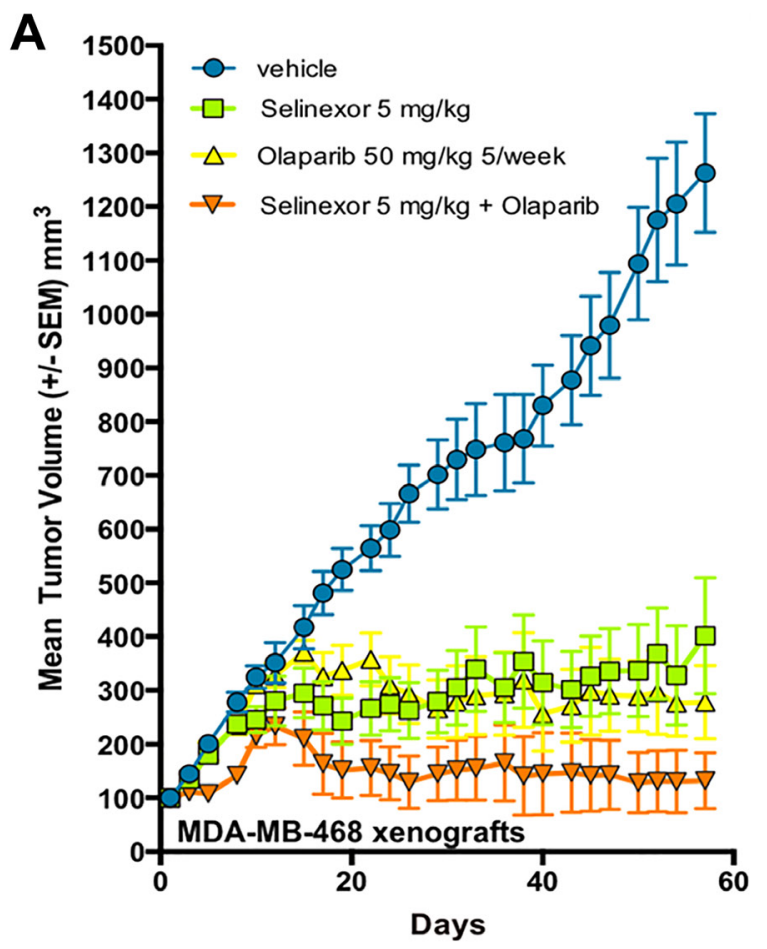

C
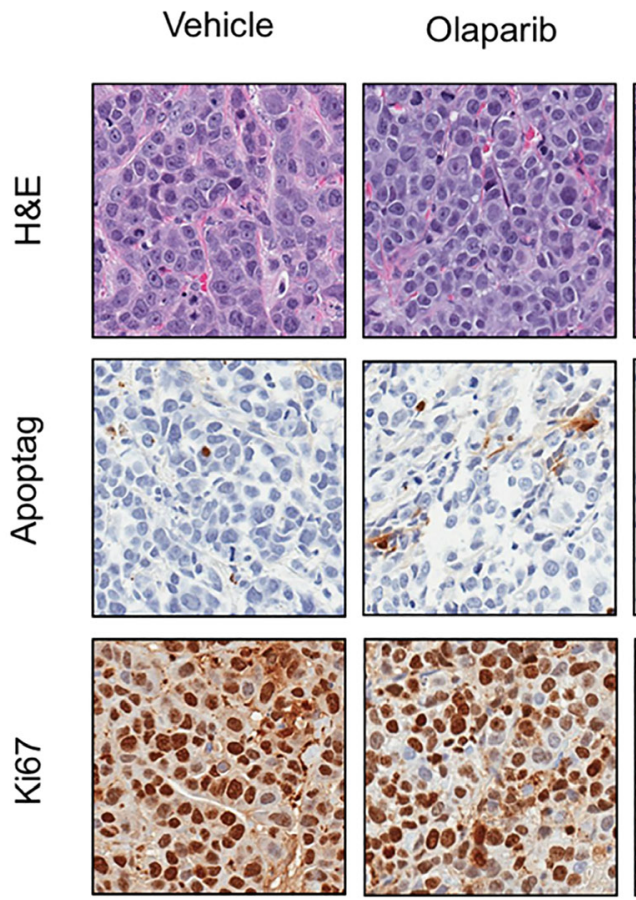

mutation status or molecular subtypes. Synergy was also observed in HER2+ BT474 cells carrying a BRCA1 mutation. Interestingly, although the TNBC cell line HCC1937 carries a $B R C A 1$ mutation, it was the least sensitive

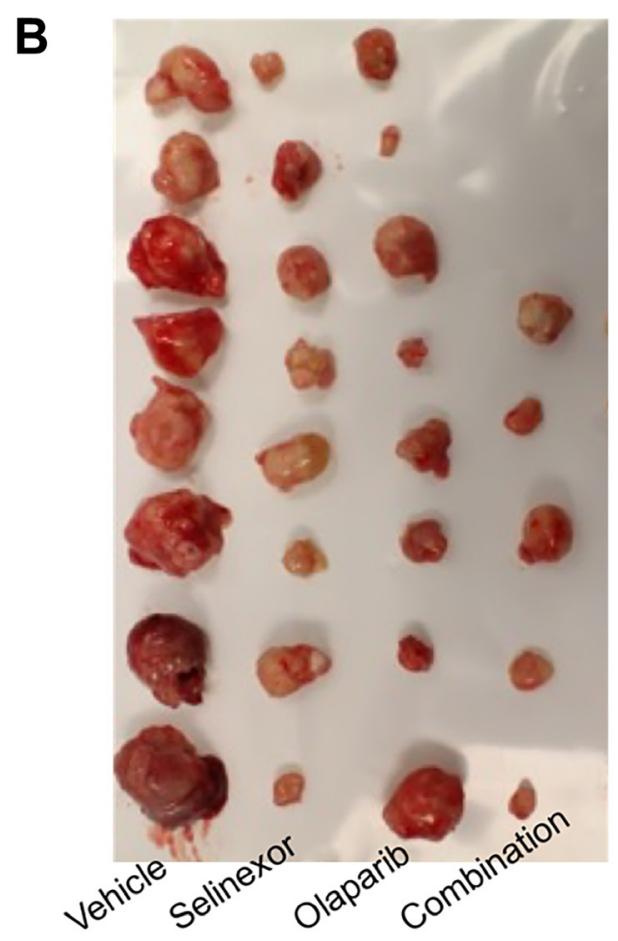

Selinexor

Combination
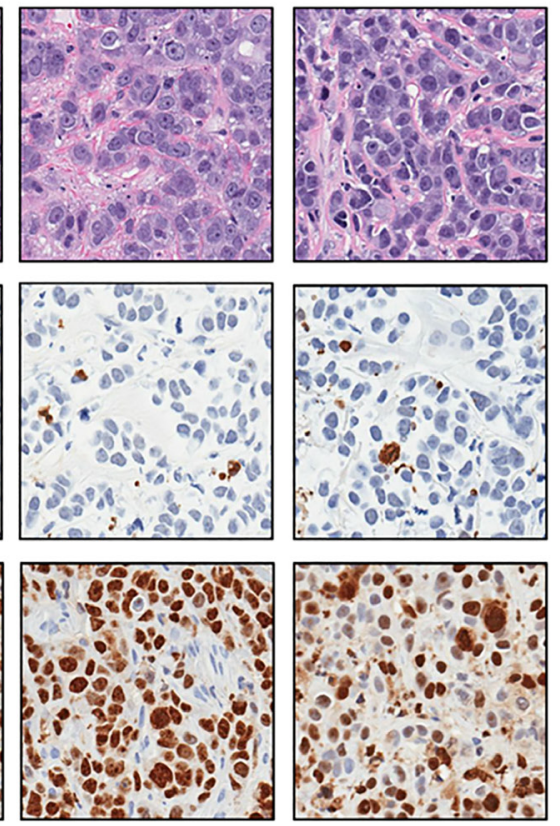

Figure 4: Synergistic effect of olaparib and selinexor on the growth of BRCA1-wt MDA-MB-468, xenografts in immunodeficient mice. (A) Volumetric growth of the tumor xenografts. Each data point represents mean tumor volume \pm SEM. Drug doses and mode of administration: olaparib $50 \mathrm{mg} / \mathrm{kg}$, intra peritoneal, 5 days/week; selinexor $5 \mathrm{mg} / \mathrm{kg}$, oral, 3 days/week. (B) Tumors from each treatment group at the end of the experiment. (C) Representative images showing staining with H\&E, ApopTag ${ }^{\circledR}$ and Ki67 of tumors from each treatment group. 
cell line to olaparib among all cell lines tested, suggesting that factors other than $B R C A$ mutations affect cancer cell sensitivity to olaparib, as also shown by other researchers [7]. The synergistic anti-tumor effects of olaparib and selinexor were also observed in mouse xenograft models of TNBC cell lines MDA-MB-468 (BRCAl-wt) and MDA-MB-436 (BRCA1-mut). Surprisingly, in the MDAMB-436-derived xenograft model, we observed a trend for bigger tumors in the olaparib group. This difference was not statistically significantly different compared to the control group and appeared only on the last day of the experiment. Several reasons could explain this observation, the main one being the exponential tumor growth that led to stopping the experiment on day 16 . Indeed, the effect of olaparib as monotherapy is generally observed only 10-15 days after the start of treatment, as was also seen in the in vivo experiment with MDAMB-468-derived xenografts. Higher doses of olaparib in this TNBC model would likely induce tumor growth inhibition as a single agent. Subtherapeutic doses of single

A

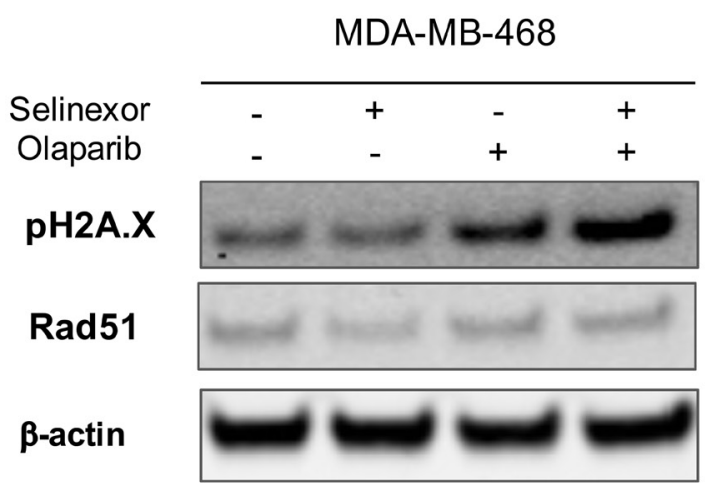

C

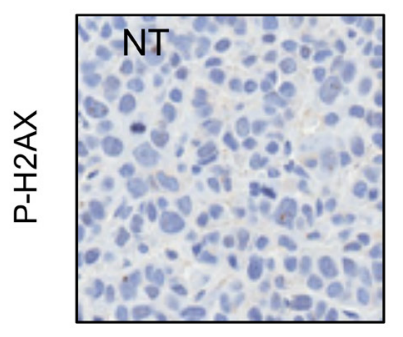

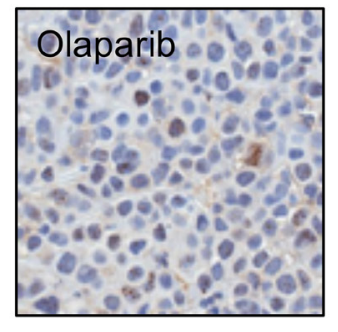

agent are often used in animal experiments designed to show synergy of combinations, and in this experiment, the synergy of selinexor and olaparib was obvious in the combination group despite a lack of efficacy with single agent olaparib at the dose tested.

DDR pathways form a complex, interacting defense mechanism against genotoxic damage. Deficient DDR is associated with increased mutational load and genome instability and often leads to neoplastic transformation and proliferation. Cells harboring DDR defects may rely on other repair pathways for survival, therefore inhibition of different DDR pathways can increase DNA damage, enhancing the sensitivity of cancer cells to therapy [27]. For this reason targeting DDR is an attractive therapeutic option [28].

Selinexor belongs to a unique class of drugs that selectively inhibit nuclear export; therefore, its mechanism of resistance may not be shared by other chemotherapeutic agents. This provides an opportunity to combine it with other therapeutic modalities such
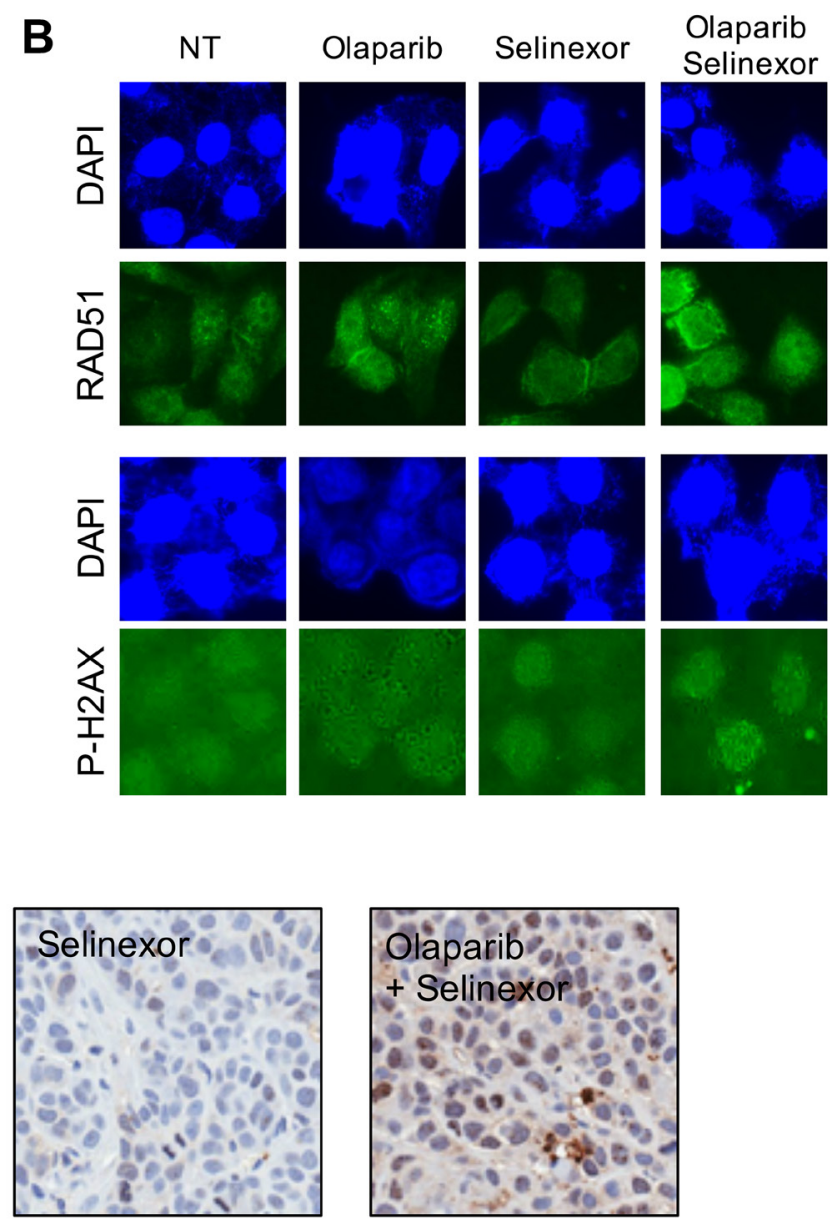

Figure 5: Effects of treatment with olaparib and selinexor (alone and in combination) on the homologous recombination pathway in MDA-MB-468 (BRCA1-wt TNBC cell). (A) Expression of RAD51 and P-H2AX in MDA-MB-468 cells. (B) RAD51 and P-H2AX protein expression by immunofluorescence in MDA-MB-468 cells exposed to olaparib and selinexor (alone or in combination) for 24 hours. (C) Immunohistochemistry of P-H2AX in representative tumors from each treatment group (xenografts were derived from MDA-MB-468 cells). 
as PARPi to increase its effectiveness. The inherent complexity of the mechanism behind XPO1 inhibition involves the ability of XPO1 to interact with major tumor suppressors and cell cycle regulators, potentially targeting multiple pathways. Selinexor has been shown to downregulate multiple proteins involved in several DDR pathways, including HR [29], thereby functioning as a chemosensitizer and radiosensitizer. Cheng et al. showed that selinexor significantly reduced tumor cell growth to approximately one-third the volume of tumors observed in 5-fluorouracil-treated animals in an in vivo breast tumor model of basal breast cancer. Reduced tumor growth was associated with a reduced percentage of cellular proliferation and an increase in apoptosis markers [14]. Selinexor as monotreatment was well tolerated even in patients having received several lines of chemotherapy for TNBC and showed a clinical benefit rate of $30 \%$, but no objective response [26]. Therefore, selinexor's more tolerable safety profile, compared with traditional chemotherapy, makes it a more desirable partner for combination therapy.

Kashyap et al. have shown that selinexor enhances the antitumor effects of DNA damage-inducing chemotherapies, in part through inhibition of DDR [29]. In addition to their role in DNA repair, PARPs are essential for many cellular processes, including chromatin remodeling, transcription, messenger RNA processing, and replication fork stabilization [30-32]. PARP inhibitors show synthetic lethality when combined with germline abnormalities in many DDR pathway components, such as mutations in ATM, ATR, BRCA1/2, CHK1, CHK2, PALB2, and RAD51 genes. Loss of several other genes involved in BRCA1-dependent HR repair, demonstrated in basal-like/TNBC cells also contribute to BRCA1-like features (sometimes termed BRCAness) [33] that confer sensitivity to olaparib. Tumors harboring DDR pathway aberrations that prevent HR repair of DSBs depend on PARP to repair $\mathrm{SSBs}$ and prevent them from progressing to irreparable, synthetically lethal DSBs [34].

The synergistic anticancer effects of olaparib and selinexor observed in TNBC cell lines regardless of their BRCA1 mutational status in our studies suggest that selinexor can potentially expand the patient population that could benefit from PARPi. In cancer cells without defects in DNA repair pathways, selinexor can reduce DNA repair proteins and sensitize cancer cells to PARP inhibition.

In addition to its effect on DNA repair pathways, several other mechanisms may contribute to the potent anti-tumor effects of selinexor in TNBC. Preclinical studies have shown that selinexor can inhibit proliferation and migration of TNBC cells by restoring the expression of arrestin-related domain-containing protein 3 (ARRDC3) [35]. Cheng et al. [14] showed that selinexor not only blocks the cytoplasm exportation of survivin - a multifunctional protein that can inhibit caspase-dependent apoptosis when it is localized in the cytoplasm - but also downregulates survivin transcription to promote apoptosis of TNBC cells.

Analysis of xenograft tumor growth derived from BRCA1-mutated and BRCA1-wildtype TNBC cell lines showed that co-treatment with selinexor and olaparib had a synergistic effect on tumor inhibition as compared to selinexor or olaparib alone. Tumors derived from $B R C A 1$ mutated cells showed increased apoptosis and decreased proliferation following combination treatment. Furthermore, tumors in mice co-treated with selinexor and olaparib were less vascularized than tumors in mice treated by a single drug, suggesting an effect of the combination treatment on inhibition of angiogenesis. Gravina et al showed significantly lower levels of angiogenetic cytokines interleukin 8 and vascular endothelial growth factor in prostate cancer cells treated with selinexor as compared to untreated controls [36].

Attiyeh et al. reported that selinexor induced a robust increase in p53 in Wilm's tumor KT-10 xenografts with cleavage of PARP apparent after the first dose of drug [37].

RAD51 expression and the rate of RAD51mediated HR are both elevated in many types of cancer, including breast cancer [38]. RAD51 facilitates metastatic dissemination in TNBC [39]; overexpression of RAD51 in $B R C A$ mutated TNBC cell lines has been linked to cell survival and proliferation [40]. Silencing RAD51 in TNBC cell lines sensitize them to the PARP inhibitor BT-888 [41]. Furthermore, a defect in HR pathway was associated with synergism between olaparib and histone deacetylase inhibitors in TNBC [42]. Analysis of the expression of proteins involved in HR following treatment with selinexor and olaparib showed that selinexor decreased RAD51 expression in MDA-MB-468 cells, consistent with Kashyap et al. [29] who showed that selinexor reduced the expression of multiple DNA repair proteins, including RAD51, CHK1, MLH1 in multiple cell lines. P-H2AX expression increased significantly in these cells after exposure to selinexor + olaparib, confirming an increase in DNA damage [43].

In addition to TNBCs, co-treatment with selinexor and olaparib can potentially benefit patients with other cancer types. A phase Ib clinical trial investigating the safety of co-treatment with selinexor and olaparib in patients with advanced solid tumors is currently ongoing (NCT02419495).

In conclusion, combination of selinexor and olaparib induces robust anti-tumor activity in vitro and in vivo in TNBC cell lines with or without a BRCA1 mutation. Our pre-clinical data support further investigation of the mechanism of action affecting this combination therapy in TNBC. 


\section{MATERIALS AND METHODS}

\section{Cell lines and culture conditions}

Eight breast cancer cell lines (Table 1) were obtained from The American Type Culture Collection (ATCC). Each cell line was verified by short tandem repeat analysis when the study was initiated. Cells were tested for Mycoplasma annually by polymerase chain reaction. Cell lines were stored in liquid nitrogen and cultured for less than 6 months. The cells were cultured in Dulbecco's modified Eagle's medium/F-12 supplemented with $10 \%$ fetal bovine serum at $37^{\circ} \mathrm{C}$ and humidified $5 \%$ $\mathrm{CO}_{2}$. The cell line characteristics are shown in Table 1.

\section{Drugs and reagents}

Selinexor was provided by Karyopharm Therapeutics Inc. Olaparib was obtained from LC Laboratories.

For in vitro experiments, selinexor and olaparib were solubilized in dimethyl sulfoxide (DMSO) and stored at $-20^{\circ} \mathrm{C}$ until use. For in vivo experiments, selinexor was prepared in $0.6 \% \mathrm{w} / \mathrm{v}$ Pluronic F-68 surfactant and $0.6 \%$ w/v PVP K-29/32 polymer. Olaparib was supplied as a crystalline powder that was dissolved in DMSO equal to $10 \%$ of the final volume. Then Solutol HS-15 was added as $10 \%$ of the final volume, and a solution of $10 \%$ hydroxypropyl- $\beta$-cyclodextrin was added to bring the final volume to the desired quantity.

\section{Cell proliferation/viability assays}

Seven TNBC cell lines (HCC-1937, MDA-MB-231, MDA-MB-436, MDA-MB-453, MDA-MB-468, Hs578T, BT-549) and one HER2-amplified BRCA-mut breast cancer cell line (BT474) were seeded in 96-well plates at densities of 3000-10000 cells per well depending on the growth characteristics of each cell line. After cells had adhered overnight, titrating concentrations of the designated drug (selinexor and/or olaparib) were added to the wells in triplicates and incubated at $37^{\circ} \mathrm{C}$ for 72 hours. Cell viability was then measured using an MTT (3-(4,5-dimethylthiazol-2-yl)-2,5-diphenyltetrazolium bromide) assay (Sigma-Aldrich).

Synergism of selinexor and olaparib was determined by combination index (CI) analysis adapted from the median-principle methods of Chou and Talalay [44]. CompuSyn 1.0 software was used for CI analysis (ComboSyn).

A CI lower than 1 defined synergism while a CI higher than 1 defined antagonism.

\section{Cell cycle analysis}

Cell cycle analysis was performed in MDA-MB-231, MDA-MB-468 and HCC-1937 cells following exposure to selinexor and/or olaparib for 24-48 hours. MDA-MB-231 cells were treated with olaparib $60 \mu \mathrm{M}$ and/or selinexor $0.2 \mu \mathrm{M}$ for 24 hours. MDA-MB-468 cells were treated with olaparib $30 \mu \mathrm{M}$ and/or selinexor $1 \mu \mathrm{M}$ for 24 hours. HCC-1937 cells were treated with olaparib $60 \mu \mathrm{M}$ and/ or selinexor $1 \mu \mathrm{M}$ for 48 hours. The cells were harvested and fixed with $70 \%$ ethanol at regular intervals. Fixed cells were stained with propidium iodide (PI) for flow cytometry analysis using BD FACScan (BD Biosciences, USA).

\section{Apoptosis assays}

HCC-1937, MDA-MB-231 and MDA-MB-468 cells were plated, treated the following day with selinexor and/or olaparib in triplicates and incubated for 48 hours (MDA-MB-231 and MDA-MB-468) and 72 hours (HCC1937). Following incubation, both floating and attached cells were collected and assayed for apoptosis using the Annexin V-FITC apoptosis detection kit (BD Biosciences) according to the manufacturer's protocol.

\section{Analysis of $B R C A$-mut and $B R C A$-wt xenografts in immunodeficient mice}

For the in vivo experiments, $5 \times 10^{6}$ MDA-MB-436 (BRCA1 mutated) cells were suspended in $100 \mu \mathrm{L}$ of phosphate-buffered saline (PBS) and mixed with $100 \mu \mathrm{L}$ of Matrigel solution (Corning). The mixture was injected subcutaneously to the upper flanks of 5-6-week-old female nu/nu athymic nude mice (Harlan Laboratories). When tumors reached a volume of $100 \mathrm{~mm}^{3}$, the mice were randomly assigned to an experimental group (5 mice/ group): (1) control group (placebo, i.e., vehicle without the drug); (2) olaparib group: the mice were injected intraperitoneally with olaparib $50 \mathrm{mg} / \mathrm{kg} 5$ times/week; (3) selinexor group: the mice received oral selinexor $7.5 \mathrm{mg} /$ kg 3 times/week; (4) selinexor + olaparib group: the mice received both olaparib and selinexor in the same dosage and mode of administration as in groups 2 and 3.

The tumors were measured twice weekly. Tumor volumes were determined using the formula A (length) $\times \mathrm{B}^{2}($ width $) \times 0.5236$. The experiment was stopped on Day 16. At the end of the study, the mice were sacrificed, and the tumors were excised, weighed and fixed in $10 \%$ neutral buffered formalin and maintained in $70 \%$ ethanol. The fixed tumors were embedded in paraffin, sectioned and stained with hematoxylin and eosin (H\&E) for histopathological examination.

A similar in vivo experiment was done with xenografts derived from MDA-MB-468 (BRCAl-wt) cells. The experimental design was the same, except for selinexor dosage which was $5 \mathrm{mg} / \mathrm{kg}, 3$ times/week. The experiment was stopped on Day 59.

Animal experiments with MDA-MB-436-derived xenografts were performed at Cedars-Sinai Medical Center and strictly followed the guidelines of Cedars- 
Sinai Medical Center and the National Institutes of Health. Animal experiments with MDA-MB-468-derived xenografts were performed by Pharma Models, LLC., and all protocols and procedures were approved by the Institutional Animal Care and Use Committee.

\section{Analysis of protein expression in MDA-MB-468 cells}

MDA-MB-468 cells were exposed to either drugfree medium or olaparib and/or selinexor. After different durations of exposure, cells were lysed with RIPA buffer (Millipore Upstate, USA) supplemented with protease inhibitor cocktail. For analysis of phosphorylated protein, a phosphatase inhibitor cocktail (PhosSTOP, Roche, Switzerland) was added to the lysis buffer. $40 \mu \mathrm{g}$ proteins were separated by SDS-PAGE, transferred to nitrocellulose membrane, and blotted with primary antibodies p-H2AX (Cell Signaling Technology, USA) and RAD51 (Santa Cruz Biotechnology, USA); $\beta$-actin was used as a loading control.

\section{Immunofluorescence}

Protein expression of RAD51 and p-H2AX were also evaluated by immunofluorescence in MDA-MB-231 and MDA-MB-468 cells after exposure to olaparib and selinexor (alone or in combination) for 24 hours: MDAMB-231 cells were exposed to $0.2 \mu \mathrm{M}$ selinexor and/or $60 \mu \mathrm{M}$ olaparib. MDA-MB-468 cells were exposed to 1 $\mu \mathrm{M}$ selinexor and/or $30 \mu \mathrm{M}$ olaparib. Sterile cover slips were placed in 12 or 24-well plates, washed with PBS and then with culture media. The coverslips were seeded with cells at a density of 10,000 cells $/ \mathrm{cm}^{2}$ and incubated for 16 hours. The next day the cells were rinsed with complete PBS, fixed for 30 minutes with 4\% formaldehyde in PBS, and then washed gently twice with PBS. The cells were quenched with $50 \mathrm{mM} \mathrm{NH}_{4} \mathrm{Cl}$ for 15 minutes, then washed with PBS for 4 minutes and blocked for 1 hour at room temperature with $1 \%$ bovine serum albumin. The cells were then incubated with primary antibodies p-H2AX (Cell Signaling Technology, USA) or RAD51 (Santa Cruz Biotechnology, USA) for one hour at room temperature or overnight at $4^{\circ} \mathrm{C}$. After incubation with the primary antibody, the cells were washed 3 times with PBS and incubated with secondary antibody (Cell Signaling Technology, USA) for 1 hour. After incubation with the secondary antibody, the coverslips were washed 3 times with PBS. Cell nuclei were counterstained with DAPI (diamidino-2-phenylindole). An antifading agent was added (Fluoromount/Slow Fade/Vectashield) and the coverslips were mounted on clean glass slides and sealed.

\section{Histology and immunohistochemistry analysis}

Xenograft samples from mouse models were fixed in $10 \%$ neutral buffered formalin and paraffin embedded.
Sections cut at $5 \mu \mathrm{m}$ were stained by routine H\&E for histology analysis. Immunohistochemistry (IHC) staining was performed as previously described [45]. Apoptosis was detected with the ApopTag kit (Millipore, Cat No. S710003). The Ki67 antibody (Cell Marque, Cat No. 275R-18) and the p-H2A.X antibody (Millipore, Cat No. 05-636) were used for IHC. Digital images of the slides were obtained through an Aperio AT Turbo scanner at $20 \times$.

\section{Abbreviations}

BRCA1-mut: BRCA1 mutant; BRCA1-wt: BRCA1 wildtype; $\mathrm{CI}$ : combination index; DDR: DNA damage repair; DMSO: dimethyl sulfoxide; DSB: double-strand DNA break; HR: homologous recombination; H\&E: hematoxylin and eosin; PARP: poly (ADP-ribose) polymerase; PARPi: poly (ADP-ribose) polymerase inhibitor; PBS: phosphate buffered saline; SEM: standard error of the mean; SSB: single strand DNA break; TGI: tumor growth inhibition; TNBC: triple-negative breast cancer.

\section{Author contributions}

Conception and design: HP Koeffler, H Marijon. Development of methodology: H Marijon, S Gery, DH Lee, HP Koefler. Acquisition of data (provided animals, acquired and managed patients, provided facilities, etc.): H Marjon, DH Lee, S Gery, H Chang. Analysis and interpretation of data (e.g., statistical analysis, biostatistics, computational analysis): H Marjon, DH Lee, S Gery, HP Koeffler, A de Gramont, Y Landesman, S Shacham, H Chang. Writing, review, and/or revision of the manuscript: H Marjon, HP Koeffler, Y Landesman, S Shacham, H Chang. Administrative, technical, or material support (i.e., reporting or organizing data, constructing databases): NA. Study supervision: HP Koeffler Y Landesman, S Shacham.

\section{ACKNOWLEDGMENTS}

Medical writing support was funded by Karyopharm Therapeutics Inc. and provided by Sharon Furman-Assaf, $\mathrm{PhD}$, under close direction of the authors.

\section{CONFLICTS OF INTEREST}

HC, YL and SS are Karyopharm employees. All other authors declare no potential conflicts of interest.

\section{FUNDING}

H. Marijon is supported by the "Fondation pour la Recherche Médicale” (FDM20140629986). 


\section{REFERENCES}

1. Siegel RL, Miller KD, Jemal A. Cancer statistics, 2020. CA Cancer J Clin. 2020; 70:7-30. https://doi.org/10.3322/ caac.21590. [PubMed]

2. O'Donovan PJ, Livingston DM. BRCA1 and BRCA2: breast/ovarian cancer susceptibility gene products and participants in DNA double-strand break repair. Carcinogenesis. 2010; 31:961-67. https://doi.org/10.1093/ carcin/bgq069. [PubMed]

3. Cancer Genome Atlas Network. Comprehensive molecular portraits of human breast tumours. Nature. 2012; 490:6170. https://doi.org/10.1038/nature11412. [PubMed]

4. Sharma P, Klemp JR, Kimler BF, Mahnken JD, Geier LJ, Khan QJ, Elia M, Connor CS, McGinness MK, Mammen JM, Wagner JL, Ward C, Ranallo L, et al. Germline BRCA mutation evaluation in a prospective triple-negative breast cancer registry: implications for hereditary breast and/or ovarian cancer syndrome testing. Breast Cancer Res Treat. 2014; 145:707-14. https://doi.org/10.1007/s10549-0142980-0. [PubMed]

5. Farmer H, McCabe N, Lord CJ, Tutt AN, Johnson DA, Richardson TB, Santarosa M, Dillon KJ, Hickson I, Knights C, Martin NM, Jackson SP, Smith GC, Ashworth A. Targeting the DNA repair defect in BRCA mutant cells as a therapeutic strategy. Nature. 2005; 434:917-21. https:// doi.org/10.1038/nature03445. [PubMed]

6. U.S Food and Drug Administration. FDA approves olaparib for germline BRCA-mutated metastatic breast cancer. 2018. https://www.fda.gov/drugs/resources-informationapproved-drugs/fda-approves-olaparib-germline-brcamutated-metastatic-breast-cancer.

7. Keung MY, Wu Y, Badar F, Vadgama JV. Response of Breast Cancer Cells to PARP Inhibitors Is Independent of BRCA Status. J Clin Med. 2020; 9:940. https://doi. org/10.3390/jcm9040940. [PubMed]

8. Vagia E, Mahalingam D, Cristofanilli M. The Landscape of Targeted Therapies in TNBC. Cancers (Basel). 2020; 12:916. https://doi.org/10.3390/cancers12040916. [PubMed]

9. Balmaña J, Tung NM, Isakoff SJ, Graña B, Ryan PD, Saura C, Lowe ES, Frewer P, Winer E, Baselga J, Garber JE. Phase I trial of olaparib in combination with cisplatin for the treatment of patients with advanced breast, ovarian and other solid tumors. Ann Oncol. 2014; 25:1656-63. https:// doi.org/10.1093/annonc/mdu187. [PubMed]

10. Bendell J, O'Reilly EM, Middleton MR, Chau I, Hochster $\mathrm{H}$, Fielding A, Burke W, Burris H 3rd. Phase I study of olaparib plus gemcitabine in patients with advanced solid tumours and comparison with gemcitabine alone in patients with locally advanced/metastatic pancreatic cancer. Ann Oncol. 2015; 26:804-11. https://doi.org/10.1093/annonc/ mdu581. [PubMed]

11. Chen EX, Jonker DJ, Siu LL, McKeever K, Keller D, Wells J, Hagerman L, Seymour L. A Phase I study of olaparib and irinotecan in patients with colorectal cancer: Canadian
Cancer Trials Group IND 187. Invest New Drugs. 2016; 34:450-57. https://doi.org/10.1007/s10637-016-0351-x. [PubMed]

12. Senapedis WT, Baloglu E, Landesman Y. Clinical translation of nuclear export inhibitors in cancer. Semin Cancer Biol. 2014; 27:74-86. https://doi.org/10.1016/j. semcancer.2014.04.005. [PubMed]

13. Abraham SA, Holyoake TL. Redirecting traffic using the XPO1 police. Blood. 2013; 122:2926-28. https://doi. org/10.1182/blood-2013-09-523670. [PubMed]

14. Cheng Y, Holloway MP, Nguyen K, McCauley D, Landesman Y, Kauffman MG, Shacham S, Altura RA. XPO1 (CRM1) inhibition represses STAT3 activation to drive a survivin-dependent oncogenic switch in triplenegative breast cancer. Mol Cancer Ther. 2014; 13:675-86. https://doi.org/10.1158/1535-7163.MCT-13-0416. [PubMed]

15. Ferreira BI, Cautain B, Grenho I, Link W. Small Molecule Inhibitors of CRM1. Front Pharmacol. 2020; 11:625. https:// doi.org/10.3389/fphar.2020.00625. [PubMed]

16. Miyake T, Pradeep S, Wu SY, Rupaimoole R, Zand B, Wen Y, Gharpure KM, Nagaraja AS, Hu W, Cho MS, Dalton HJ, Previs RA, Taylor ML, et al. XPO1/CRM1 Inhibition Causes Antitumor Effects by Mitochondrial Accumulation of eIF5A. Clin Cancer Res. 2015; 21:3286-97. https://doi. org/10.1158/1078-0432.CCR-14-1953. [PubMed]

17. Ranganathan $\mathrm{P}, \mathrm{Yu} \mathrm{X}$, Santhanam R, Hofstetter J, Walker A, Walsh K, Bhatnagar B, Klisovic R, Vasu S, Phelps MA, Devine S, Shacham S, Kauffman M, et al. Decitabine priming enhances the antileukemic effects of exportin 1 (XPO1) selective inhibitor selinexor in acute myeloid leukemia. Blood. 2015; 125:2689-92. https://doi. org/10.1182/blood-2014-10-607648. [PubMed]

18. Turner JG, Dawson J, Sullivan DM. Nuclear export of proteins and drug resistance in cancer. Biochem Pharmacol. 2012; 83:1021-32. https://doi.org/10.1016/j. bcp.2011.12.016. [PubMed]

19. Yue L, Sun ZN, Yao YS, Shen Z, Wang HB, Liu XP, Zhou F, Xiang JY, Yao RY, Niu HT. CRM1, a novel independent prognostic factor overexpressed in invasive breast carcinoma of poor prognosis. Oncol Lett. 2018; 15:751522. https://doi.org/10.3892/ol.2018.8316. [PubMed]

20. Turner JG, Dawson J, Emmons MF, Cubitt CL, Kauffman M, Shacham S, Hazlehurst LA, Sullivan DM. CRM1 Inhibition Sensitizes Drug Resistant Human Myeloma Cells to Topoisomerase II and Proteasome Inhibitors both In Vitro and Ex Vivo. J Cancer. 2013; 4:614-25. https://doi. org/10.7150/jca.7080. [PubMed]

21. Schmidt J, Braggio E, Kortuem KM, Egan JB, Zhu YX, Xin CS, Tiedemann RE, Palmer SE, Garbitt VM, McCauley D, Kauffman M, Shacham S, Chesi M, et al. Genome-wide studies in multiple myeloma identify XPO1/CRM1 as a critical target validated using the selective nuclear export inhibitor KPT-276. Leukemia. 2013; 27:2357-65. https://doi.org/10.1038/leu.2013.172. [PubMed] 
22. Tai YT, Landesman Y, Acharya C, Calle Y, Zhong MY, Cea M, Tannenbaum D, Cagnetta A, Reagan M, Munshi AA, Senapedis W, Saint-Martin JR, Kashyap T, et al. CRM1 inhibition induces tumor cell cytotoxicity and impairs osteoclastogenesis in multiple myeloma: molecular mechanisms and therapeutic implications. Leukemia. 2014; 28:155-65. https://doi.org/10.1038/leu.2013.115. [PubMed]

23. Turner JG, Marchion DC, Dawson JL, Emmons MF, Hazlehurst LA, Washausen P, Sullivan DM. Human multiple myeloma cells are sensitized to topoisomerase II inhibitors by CRM1 inhibition. Cancer Res. 2009; 69:6899-905. https://doi.org/10.1158/0008-5472.CAN-090484. [PubMed]

24. Gandhi UH, Senapedis W, Baloglu E, Unger TJ, Chari A, Vogl D, Cornell RF. Clinical Implications of Targeting XPO1-mediated Nuclear Export in Multiple Myeloma. Clin Lymphoma Myeloma Leuk. 2018; 18:335-45. https://doi. org/10.1016/j.clml.2018.03.003. [PubMed]

25. Arango NP, Yuca E, Zhao M, Evans KW, Scott S, Kim C, Gonzalez-Angulo AM, Janku F, Ueno NT, Tripathy D, Akcakanat A, Naing A, Meric-Bernstam F. Selinexor (KPT-330) demonstrates anti-tumor efficacy in preclinical models of triple-negative breast cancer. Breast Cancer Res. 2017; 19:93. https://doi.org/10.1186/s13058-017-0878-6. [PubMed]

26. Shafique M, Ismail-Khan R, Extermann M, Sullivan D, Goodridge D, Boulware D, Hogue D, Soliman H, Khong H, Han HS. A Phase II Trial of Selinexor (KPT330) for Metastatic Triple-Negative Breast Cancer. Oncologist. 2019; 24:887-e416. https://doi.org/10.1634/ theoncologist.2019-0231. [PubMed]

27. Curtin NJ. Inhibiting the DNA damage response as a therapeutic manoeuvre in cancer. Br J Pharmacol. 2013; 169:1745-65. https://doi.org/10.1111/bph.12244. [PubMed]

28. Bouwman P, Jonkers J. The effects of deregulated DNA damage signalling on cancer chemotherapy response and resistance. Nat Rev Cancer. 2012; 12:587-98. https://doi. org/10.1038/nrc3342. [PubMed]

29. Kashyap T, Argueta C, Unger T, Klebanov B, Debler S, Senapedis W, Crochiere ML, Lee MS, Kauffman M, Shacham S, Landesman Y. Selinexor reduces the expression of DNA damage repair proteins and sensitizes cancer cells to DNA damaging agents. Oncotarget. 2018; 9:30773-86. https://doi.org/10.18632/oncotarget.25637. [PubMed]

30. Michelena J, Lezaja A, Teloni F, Schmid T, Imhof R, Altmeyer M. Analysis of PARP inhibitor toxicity by multidimensional fluorescence microscopy reveals mechanisms of sensitivity and resistance. Nat Commun. 2018; 9:2678. https://doi. org/10.1038/s41467-018-05031-9. [PubMed]

31. Morales J, Li L, Fattah FJ, Dong Y, Bey EA, Patel M, Gao J, Boothman DA. Review of poly (ADP-ribose) polymerase (PARP) mechanisms of action and rationale for targeting in cancer and other diseases. Crit Rev Eukaryot Gene Expr. 2014; 24:15-28. https://doi.org/10.1615/ critreveukaryotgeneexpr.2013006875. [ubMed]
32. Murthy P, Muggia F. PARP inhibitors: clinical development, emerging differences, and the current therapeutic issues. Cancer Drug Resistance. 2019; 2:665-79. https://doi. org/10.20517/cdr.2019.002.

33. Hubalek M, Czech T, Müller H. Biological Subtypes of Triple-Negative Breast Cancer. Breast Care (Basel). 2017; 12:8-14. https://doi.org/10.1159/000455820. [PubMed]

34. Noordermeer SM, van Attikum H. PARP Inhibitor Resistance: A Tug-of-War in BRCA-Mutated Cells. Trends Cell Biol. 2019; 29:820-34. https://doi.org/10.1016/j. tcb.2019.07.008. [PubMed]

35. Soung YH, Kashyap T, Nguyen T, Yadav G, Chang H, Landesman Y, Chung J. Selective Inhibitors of Nuclear Export (SINE) compounds block proliferation and migration of triple negative breast cancer cells by restoring expression of ARRDC3. Oncotarget. 2017; 8:52935-47. https://doi.org/10.18632/oncotarget.17987. [PubMed]

36. Gravina GL, Tortoreto M, Mancini A, Addis A, Di Cesare E, Lenzi A, Landesman Y, McCauley D, Kauffman M, Shacham S, Zaffaroni N, Festuccia C. XPO1/CRM1selective inhibitors of nuclear export (SINE) reduce tumor spreading and improve overall survival in preclinical models of prostate cancer (PCa). J Hematol Oncol. 2014; 7:46. https://doi.org/10.1186/1756-8722-7-46. [PubMed]

37. Attiyeh EF, Maris JM, Lock R, Reynolds CP, Kang MH, Carol H, Gorlick R, Kolb EA, Keir ST, Wu J, Landesman Y, Shacham S, Lyalin D, et al. Pharmacodynamic and genomic markers associated with response to the XPO1/ CRM1 inhibitor selinexor (KPT-330): A report from the pediatric preclinical testing program. Pediatr Blood Cancer. 2016; 63:276-86. https://doi.org/10.1002/pbc.25727. [PubMed]

38. Klein HL. The consequences of Rad51 overexpression for normal and tumor cells. DNA Repair (Amst). 2008; 7:68693. https://doi.org/10.1016/j.dnarep.2007.12.008. [PubMed]

39. Wiegmans AP, Al-Ejeh F, Chee N, Yap PY, Gorski JJ, Da Silva L, Bolderson E, Chenevix-Trench G, Anderson R, Simpson PT, Lakhani SR, Khanna KK. Rad51 supports triple negative breast cancer metastasis. Oncotarget. 2014; 5:3261-72. https://doi.org/10.18632/ oncotarget.1923. [PubMed]

40. Martin RW, Orelli BJ, Yamazoe M, Minn AJ, Takeda $\mathrm{S}$, Bishop DK. RAD51 up-regulation bypasses BRCA1 function and is a common feature of BRCA1-deficient breast tumors. Cancer Res. 2007; 67:9658-65. https://doi. org/10.1158/0008-5472.CAN-07-0290. [PubMed]

41. Wiegmans AP, Miranda M, Wen SW, Al-Ejeh F, Möller A. RAD51 inhibition in triple negative breast cancer cells is challenged by compensatory survival signaling and requires rational combination therapy. Oncotarget. 2016; 7:60087100. https://doi.org/10.18632/oncotarget.11065. [PubMed]

42. Marijon H, Lee DH, Ding L, Sun H, Gery S, de Gramont A, Koeffler HP. Co-targeting poly (ADP-ribose) polymerase (PARP) and histone deacetylase (HDAC) in triple-negative breast cancer: Higher synergism in BRCA mutated cells. 
Biomed Pharmacother. 2018; 99:543-51. https://doi. org/10.1016/j.biopha.2018.01.045. [PubMed]

43. Bonner WM, Redon CE, Dickey JS, Nakamura AJ, Sedelnikova OA, Solier S, Pommier Y. GammaH2AX and cancer. Nat Rev Cancer. 2008; 8:957-67. https://doi. org $/ 10.1038 / \mathrm{nrc2523}$. [PubMed]

44. Chou TC. Drug combination studies and their synergy quantification using the Chou-Talalay method. Cancer Res. 2010; 70:440-46. https://doi.org/10.1158/0008-5472.CAN09-1947. [PubMed]
45. Wang AY, Weiner $\mathrm{H}$, Green $\mathrm{M}$, Chang $\mathrm{H}$, Fulton $\mathrm{N}$, Larson RA, Odenike O, Artz AS, Bishop MR, Godley LA, Thirman MJ, Kosuri S, Churpek JE, et al. A phase I study of selinexor in combination with high-dose cytarabine and mitoxantrone for remission induction in patients with acute myeloid leukemia. J Hematol Oncol. 2018; 11:4. https://doi. org/10.1186/s13045-017-0550-8. [PubMed] 